\title{
Postos comunitários: uma alternativa para o sistema de saúde
}

\author{
Community health centers: \\ an alternative for the health system
}

João Claudio Lara Fernandes 1 João Guerra de Castro Montei ro 1

\footnotetext{
1 Posto de Saúde da Associação dos Moradores e Amigos do Bairro Barcellos. Travessa Flores 4, Favela da Rocinha, Rio de Janeiro, RJ 22451-000, Brasil.
}

Abstract Reflecting on the current reorganization of the relationship between the state and civil society, the health care field is involved in an intense debate over the organization and use of government and private health services. The authors propose an alternative, consisting of the implementation of primary health care clinics, managed by local institutions and funded by the Unified Health System. To support this proposition, they report on the current experience at the Rocinha sl um in Rio de Janeiro, where a community health center was built by the neighborhood association 12 years ago and has been managed by the community since then. The hospital referral rate at the clinic, requests for laboratory tests, and use of precriptions have been consi derably limited, although these services are available. These low rates are attributed to the possibility of closer social control by the community, as well as to the geographical features of the center, favoring a broader perception of both health problems and treatment. In order to provide more substantial support to the proposed centers, some suggestions are presented, li ke the implementation of direct agreements between the government and nei ghborhood associations (not allowed under current legislation) and expanding potential sources of funding for the health centers, currentl y restricted to government programs.

Key words Primary Health Care; Consumer Participation; Health System; Heal th Policy

Resumo Consi derando a atual conjuntura de reorganização das relações entre o Estado e a soci edade civil, os autores propõem, para a área da saúde, uma alternativa intermediária entre as propostas estatizantes e privati zantes, que consi ste na organização de postos de saú de geri dos por enti dades locais e conveni ados ao Sistema Ú ni co deSaúde. Para sustentar esta proposição, éapresentada a experiência desenvolvida há 12 anos na favel a da Rocinha, onde uma associação de moradores construiu e administra um serviço de saúde. É destacada a efi ciência do trabal ho, o que é atri buído a um mai or controle social sobre o serviço, bem como às suas característi cas geográfi cas, que favorecem a utilização de abordagens terapêuticas diversi ficadas. São apresentadas propostas que visam a dar uma maior sustentação a esta alternativa, como a el aboração de convênios diretos com associações de moradores, atualmente impedi dos pela regulamentação do Ministério da Saúde, ea ampli ação a estes postos de al guns critérios de remuneração, ora restritos a instituições governamentais.

Palavras-chave Cuidados Primários de Saúde; Partici pação Comunitária; Sistema de Saúde; Políticas de Saúde 


\section{Introdução}

As profundas mudanças que vêm ocorrendo nas relações entre o Estado e a sociedade civil tendem a conferir uma importância cada vez maior às organizações comunitárias, não só no nível da representação política, como também no campo da implementação e gestão de serviços locais. Esta tendência, entretanto, tem se manifestado de forma ainda bastante restrita no que se refere à área da assistência à saúde. Nesta, não obstante os avanços obtidos com a Constituição de 1988, a realidade vivida no cotidiano de milhões de cidadãos se caracteriza por filas, atendimento precário e falta de espaços participativos. Ademais, o embate políticoideológi co existente nesta área tem tido como protagonistas principais os setores governamental e privado, e é ainda rara a apresentação de al ternativas baseadas na criação de parcerias e utilização do potencial dos organismos comunitários. Isto decorre, entre outras razões, do fato de que aqueles setores encontram-se politicamente mais organizados, enquanto que este último, ao contrário, mostra-se ainda frágil, principalmente nesta área específica. Não devemos esquecer, aqui, que a problemática da assistência à saúde recai basicamente sobre as camadas com menor poder de influência política e, portanto, não alcança a percepção de transcendência de outras questões, como a violência, o meio ambiente etc., que atingem segmentos mais amplos e politicamente mais articulados da população. Em função disto, é forçoso reconhecer que, ainda que a crise no setor saúde possua um certo espaço na mídia, o que vem acontecendo, na realidade, é um processo de normalização da desassistência e da morte por falta de cuidados de saúde adequados.

O presente trabal ho tem a intenção de incentivar este debate, através da apresentação de uma experiência que vem sendo desenvolvida há 12 anos na favela da Rocinha, em um posto de saúde construído pela comunidade e administrado pela Associação de Moradores local. O acompanhamento deste processo permite, agora, defender seu potencial como uma alternativa viável para a organização da atenção primária à saúde em áreas urbanas, abrindo um caminho intermediário, entre o setor público governamental e o setor privado, na prestação de assistência. Devemos, desde já, deixar claro que a contribuição que esperamos dar com este texto refere-se basicamente ao tipo de conceituação que estamos dando àquela experiência, já que a existência, em si, de um serviço comunitário de saúde não é um fato que tenha, em absoluto, qualquer originalidade. Devemos assinalar, também, que estaremos utilizando o termo "comunidade" no sentido de uma população social e culturalmente identificada com base em um determinado espaço geográfico, enfatizando, embora de modo não excludente, os segmentos populares urbanos.

Para um melhor entendimento desta apresentação, precisaremos abordar, sucintamente, algumas questões preliminares que constituem premissas básicas de nossa proposição.

\section{Pobreza e cidadania}

As mudanças atualmente observadas no papel do Estado vêm apontando uma tendência ao esvaziamento de sua função de provedor do bem-estar social, dando lugar a um vasto conjunto de propostas que têm em comum a crítica à ineficiência e, principalmente, à inviabilidade econômica da centralização estatal. Uma parte bastante influente destas proposições aponta diretamente para o mercado enquanto alternativa para o desenvolvimento. Outras buscam reduzir a demanda social ao Estado através do fortalecimento da sociedade civil enquanto parceira e agente de políticas públicas, o que Rosanvallon (1985) denomina de "redução positiva" do papel do Estado. Este termo se justifica, na medida em que a mera minimização do aparelho estatal (uma redução negativa), defendida por setores liberais, mostra-se incapaz de conduzir a um desenvolvimento social adequado, acentuando a concentração de renda e a exclusão de grupos populacionais cada vez mais amplos do acesso aos bens de consumo, levando, com isto, ao aumento da miséria e da violência. Esta redução positiva, segundo o mesmo autor, estaria baseada em três aspectos principais: a socialização, que se refere à desburocratização e racionalização gerencial dos grandes equipamentos e funções coletivas; a descentralização, que tem o objetivo de remodelar certos serviços públicos, tornando-os mais próximos dos usuários e a autonomização, que significa a transferência a coletividades não públicas (associações, fundações etc.) de tarefas relacionadas ao serviço à população (Rosanvallon, 1985). Cabe comentar, nesta conceituação, que não se trata, em nosso ponto de vista, de distinguir as "coletividades públicas" das "não públicas", uma vez que fundações e associações não estão menos obrigadas a um compromisso com o bem-estar social do que qualquer entidade governamental. É preciso distinguir a característica pública, presente em ambos os casos, de uma relação institu- 
cional específica, de vinculação direta ao governo, na primeira situação, e sem este vínculo, na segunda.

Trata-se, portanto, de buscar alternativas de formulação, gestão e execução de políticas sociais que apresentem uma melhor relação entre a eficiência e a eqüidade, rompendo-se com posturas apriorísticas que acabam não levando em consideração, afinal, o bem-estar público, no seu sentido mais objetivo. Exemplos destas alternativas já têm sido experimentados em situações diversas, al gumas delas com resultados encorajadores, como é o caso da experiência das cidades saudáveis, desenvolvida principalmente no Canadá (Lacombe \& Poirier, 1992). Pode-se dizer que uma vertente considerável do movimento das ONGs situa-se também nesta perspectiva, bem como várias ações de solidariedade social que vêm surgindo em nosso país, que visam a resgatar o aspecto propositivo da cidadania na realização do desenvolvimento social.

Esta tendência, entretanto, assim como o próprio conceito de cidadania a ela associado não são isentos de problemas, particularmente quando avaliados sob a ótica da relação entre as diversas camadas sociais. Duarte et al. (1993), por exemplo, analisam o que eles denominam de "processo de cidadanização", e fazem um paralelo deste com o conceito de poder disciplinar de Foucault, referindo a existência de uma ambigüi dade entre "a legitimidade do discurso e dos projetos dos 'interventores' e a legitimidade da percepção e do cotidiano da grande maioria da população". De fato, é preciso reconhecer que a maior parte dos movimentos de solidariedade a que nos referimos anteriormente, embora apresentem uma série de aspectos positivos, têm como característica comum o fato de pertencerem a setores da classe média urbana, que se propõem a "levar" às classes populares projetos de desenvolvimento, geralmente idealizados e planejados por aquele mesmo setor social.

Acreditamos, no entanto, que a dinâmica de inclusão social deve pressupor não só o direito de acesso aos equipamentos públicos, mas o reconhecimento da capacidade criativa, propositiva e gerencial das camadas populares, que, aliás, é demonstrada continuamente, através de inúmeras iniciativas e movimentos próprios. Em função da própria precariedade em que vive este segmento, a maioria destas iniciativas não é conhecida, sobrevivendo com grandes dificuldades, o que provoca uma percepção comum de que inexistem e reforça uma imagem passiva das comunidades pobres, quando não a de "lugares de marginais".
É preciso, portanto, analisar mais criticamente este processo de reorganização social, e reconhecer a importância da legitimação do potencial organizativo comunitário na estruturação de alternativas para um desenvolvimento mais equilibrado. Não se trata, aqui, de fazer qualquer apologia idealista deste potencial, cujas fragilidades são bastante conhecidas, principalmente no que diz respeito à falta de estrutura, pouca participação, fraca densidade representativa etc., mas de assinalar sua existência, que poderá se converter em uma maior força construtiva, à proporção que seja percebido e valorizado.

\section{Participação comunitária \\ e políticas públicas}

Considerando estas colocações, podemos aprofundar um pouco mais o aspecto específico da participação social nas políticas públicas. Em primeiro lugar, deve-se admitir que, em termos gerais, existe ainda um nível bastante baixo de participação da população na discussão destas políticas, o que pode ser explicado por uma série de fatores culturais, históricos e políticos que não cabe aqui aprofundar. Entretanto, também é preciso considerar que as formas participativas das camadas populares não são, necessariamente, semelhantes às de outros segmentos populacionais. Desta forma, nas favelas, por exemplo, pode-se constatar a partici pação dos moradores em diversas atividades, como jogos, comemorações, nas escolas de samba, em movimentos solidários espontâneos etc., reflexos de seu universo de cultura, interesses e possibilidades, eque, inclusive, em muitas ocasiões, supera amplamente as experiências de outras camadas sociais. Deste ponto de vista, o conceito de "pouca participação" mostra-se impreciso, e seria mais adequado avaliar de "qual participação" estamos tratando. É preciso, então, buscar entender por que o processo de discussão das políticas públicas não tem atraído a participação dos setores populares da mesma forma ou na mesma intensidade que aquelas outras questões.

Para tentar responder a esta pergunta, precisaremos, inicialmente, reconhecer que a participação comunitária não deve ser considerada uma tarefa de cuja importância as pessoas devem ser convencidas. De fato, em qualquer lugar existem pessoas dispostas a participar de acontecimentos que elas percebam como sendo do seu campo de interesses e possibilidades, isto é, que elas reconheçam como importantes 
e sobre os quais se sintam com poder de influenciar e adaptar às suas necessidades. 0 processo participativo, portanto, envolve relações culturais e políticas, que são muitas vezes ocultas por trás de uma pretensa comunhão de interesses. Por exemplo, uma vez que, nas discussões sobre políticas públicas, são colocados aspectos técnicos, cujas especificidades as pessoas leigas sentem dificuldade em entender, e tendo em vista que este tipo de situação traduz, na prática, a existência de instâncias diferenciadas de poder (em função do saber), a adesão da população a estes debates acaba tendo um caráter meramente legitimador das posições dos "outros" (técnicos, políticos etc.). Para ilustrar este aspecto, podemos citar uma pesquisa para avaliação do Sistema ú nico de Saúde (SUS), realizada em quatro municípios do Rio de Janeiro, onde foi relatada a dificuldade de participação popular nos Conselhos Municipais de Saúde, em função da linguagem restritiva utilizada pelos técnicos, nestes espaços (IMS-UERJ, 1993). Almeida e Campos (1988) também referem, em relação a estes conselhos, que "a erudição de algumas discussões dificulta sobremaneira a emissão de opinião por parte dos 'leigos'". Podemos supor com isto que em muitos fóruns de debate de políticas públicas deve ocorrer a hegemonia de um determinado tipo de conhecimento, amplamente legitimado socialmente, e que confere aos participantes não detentores deste conhecimento uma posição desvantajosa politicamente. Esta situação lembra a imagem sempre atual de Paulo Freire (1975), das "vasil has a serem enchidas", que é como são tratadas as pessoas comuns, cujo conhecimento e experiência de vida não são valorizados, permitindo, com isto, a manutenção de uma determinada hegemonia política. Deste ponto de vista, a falta de participação social em alguns espaços e movimentos bem pode ser interpretada como um ato de sabedoria popular.

Queremos, com estas reflexões, situar a questão da participação comunitária a partir das relações de poder subjacentes aos diversos projetos públicos. Neste sentido, o desenvolvimento de modelos organizativos de prestação de serviços - no nosso caso, de assistência à saúde -, nos quais a população tenha um poder objetivo, pode conduzir a um nível sensivelmente mais elevado de participação e controle social, contribuindo, desta forma, para um padrão de desenvolvimento mais sustentado e para a própria eficiência e adequação destes serviços.
Atenção primária à saúde e organização do sistema de saúde

Focalizemos agora, mais especificamente, o campo da assistência à saúde. Uma primeira questão a ser ressaltada refere-se ao papel ordenador da Atenção Primária à Saúde (APS), em relação ao sistema de saúde em geral. Este aspecto já tem sido bastante reconhecido, e acreditamos não ser necessário nos alongarmos aqui. Apenas para sinalizarmos este ponto, podemos citar a Organização Panamericana de Saúde (1987), que propõe a APS como uma "estratégia ou uma política integral de saúde que compreende e afeta toda a população e o Sistema de Saúde em todos os seus níveis". Mais convincente ainda, na nossa opinião, é o relato cotidiano de diretores de hospitais públicos, cronicamente às voltas com excessos de demanda, em boa parte resultantes de uma infra-estrutura ambulatorial inadequada do ponto de vista quantitativo e qualitativo.

Um estudo realizado no Posto de Saúde da Associação dos Moradores e Amigos do Bairro Barcellos (PS.AMABB), em 1986 - época em que o posto cobrava dos moradores as consultas fornecidas -, mostrava que $64 \%$ da demanda ao serviço era constituída por beneficiários do INAMPS, com direito à assistência gratuita (PS.AM ABB, 1986). Estas pessoas, embora pobres, preferiam pagar para obter um atendimento próximo às suas casas, feito de forma atenciosa por profissionais conhecidos. Com este exemplo, queremos frisar que os esforços racionalizadores da assistência hospitalar que se baseiam na noção de que a população deve ser "ensinada" a procurar os locais adequados para o atendimento ambulatorial traduzem uma postura preconceituosa, que leva, de fato, a uma política de repressão de demanda e de desassistência, em virtude da precariedade da rede extra-hospitalar. O mesmo pode ser dito das propostas de regionalização do atendimento, quando, igualmente, baseadas em táticas repressivas. Além de eticamente problemáticas, estas atitudes são, usualmente, condenadas ao fracasso, já que a população, numa contínua demonstração de criatividade, desenvolve um sem número de estratégias para driblar os controles institucionais. Uma abordagem mais coerente deste problema deve reconhecer o efeito ordenador da assistência extra-hospitalar e defender a necessidade de desenvolvimento deste campo assistencial como condição de possibilidade de organização do sistema de saúde em geral.

Um dos motivos da fragilidade desta área de assistência decorre do fato de que, histori- 
camente, as políticas de saúde têm tido como uma de suas características principais o investimento no espaço hospitalar. Este fato, por sua vez, pode ser atribuído, em parte, à hegemonia de um modelo assistencial baseado na doutrina flexneriana (Novaes, 1990), que privilegiou a formação médica hospitalar, em detrimento do ensino ambulatorial e comunitário. Por um outro viés, o próprio desenvolvimento epistemológico da medicina apresenta uma inter-relação direta com o espaço hospitalar, como nos demonstrou Foucault (1987), o que poderia explicar um certo desconforto comumente observado entre os profissionais de saúde na atuação ambulatorial. Embora não possamos aprofundar aqui estas questões, queremos indicar que existe um requisito teórico diferenciado na prática ambulatorial e comunitária, que demanda a associação do referencial fisiopatológico a outros campos de conhecimento, e cuja ausência acaba levando os profissionais a uma atuação freqüentemente desinteressa$\mathrm{da}$, ineficaz e medicalizadora, fruto de sua incapacidade de relacionamento das queixas clínicas aos seus contextos subjacentes (Fernandes, 1996).

A inexistência deste estatuto diferenciado para a prática médica ambulatorial e comunitária poderia explicar o fato de que, enquanto a área hospitalar apresenta uma certa uniformidade em relação às suas referências teóricas e procedimentos técnicos, o que se observa no campo extra-hospitalar é uma multiplicidade de definições, denominações e tipos de atuação. O próprio conceito de APS tem se prestado a uma série de ambigüidades, ora significando um tipo de assistência seletiva, voltado a grupos populacionais específicos, a partir de uma observação epidemiológica, ora um tipo de assistência adaptada, através de tecnologias simplificadas, às condições dos países pobres, ou de populações pobres em geral. De um modo coerente com as observações que fizemos até aqui, defendemos a APS enquanto um campo específico de atuação, do ponto de vista dos instrumentais teóricos utilizados, e diretamente relacionado, como referem Rifkin \& Walt (1986), à definição de "quem controla os investimentos e resultados das ações de saúde, e ao tempo realisticamente necessário para obter estes resultados". Este conceito tem sido denominado de atenção primária compreensiva, e se refere a um processo onde a participação é inerente ao próprio método de trabalho, já que este lida com situações mais abrangentes da vida, conhecidas pela clientela, que são confrontadas com o instrumental técnico-científico, daí resultando proposições terapêuticas que podem abranger diversos campos do conhecimento, tanto ao nível individual, quanto coletivo.

Apesar do tratamento superficial dado a estas questões, queremos, ao levantá-las, sinalizar que não basta a simples estruturação de serviços ambulatoriais, se esta não for acompanhada também por uma reestruturação cognitiva, das referências teóricas dos profissionais envolvidos. Cabe às universidades proporcionar os meios para uma formação técnica mais sistemática, o que, por sua vez, poderá ser incentivado a partir da ampliação deste mercado de trabalho.

\section{Histórico do posto de saúde}

da Associação dos Moradores e Amigos do Bairro Barcellos (PS.AMABB)

A favela da Rocinha possui cerca de cem mil habitantes, que dividem uma área de aproximadamente $6 \mathrm{~km}^{2}$. Apesar de estar situada em uma região de al ta concentração de unidades hospitalares públicas (Zona Sul do Rio de Janeiro), sua população não dispõe de assistência adequada em virtude do estrangulamento e excesso de demanda observados naquelas unidades. Isto foi manifestado objetivamente quando, em 1982, a Associação dos Moradores e Amigos do Bairro Barcellos (AMABB), que congrega os moradores de uma parte da favela, realizou um inquérito para saber as demandas prioritárias da comunidade. A principal necessidade apontada, nesta ocasião, referia-se à assistência à saúde. A Associação, então, obteve um financiamento externo e apoio da prefeitura, construindo, em mutirão, um pequeno posto de saúde, inaugurado em 1983. Nos primeiros anos, este posto foi financiado por entidades estrangeiras, ou cobraram-se consultas, procedimentos incapazes de assegurar a manutenção de uma equipe profissional estável. Em 1987, obteve-se um primeiro convênio com o governo (modelo Inamps/ Filantrópicas), em conjunto com as Associações de Moradores do Chapéu Mangueira, situada no Leme, e Santa Marta, no bairro de Botafogo, as quais também possuíam postos de saúde.

Este convênio refletia uma conjuntura governamental circunstancialmente favorável e apresentava uma série de fragilidades, tendo sido suspenso em 1992, o que resultou no encerramento dos três trabalhos de saúde. O posto da AMABB permaneceu fechado entre janeiro e setembro de 1993, conseguindo ser reaberto, precariamente, com a volta do sistema de cobrança de consultas. Enquanto isto, a Associa- 
ção se mobilizava no sentido de obter um novo convênio com o governo, mais bem estruturado que o anterior, o que foi finalmente conseguido em junho de 1994, também através da intermediação de uma entidade filantrópica.

\section{Estrutura gerencial do PS.AMABB}

O posto é administrado pela diretoria da $A M A B B$, que é responsável por toda a administração de recursos humanos, materiais e financeiros. Este gerenciamento é supervisionado pela Comissão de Saúde, que se reúne semanalmente e é aberta a moradores, diretores da associação e técnicos. A Comissão avalia o funcionamento do serviço, apresenta reclamações e sugestões da clientela, aprova as prestações de contas feitas pela diretoria, além de definir e planejar as ações de saúde a serem realizadas. Além desta, existe uma reunião semanal da equipe técnica, onde são aprofundadas as questões surgi das na Comissão de Saúde e delineados os aspectos metodológicos do trabaIho.

Esta estrutura foi sendo criada em função dos obstáculos que surgiam no serviço. Um deles refere-se às dificuldades no relacionamento entre diretores da associação e técnicos, decorrentes em boa parte do fenômeno de inversão dos papéis sociais, pois os profissionais passavam a ter como patrões pessoas de uma camada historicamente inferior na hierarquia social. Por outro lado, verificou-se a necessidade de garantir formas de sustentação política e controle sobre a diretoria, em virtude de sua fragilidade institucional. Deste modo, a criação de um modelo gerencial baseado em três espaços institucionais distintos - diretoria, equipe técnica, comissão de saúde -, regulamentados por um regimento interno, passou a permitir uma melhor mediação dos conflitos e uma prática participativa mais dinâmica.

\section{Aspectos técnicos do posto de saúde}

O modelo assistencial desenvolvido no posto se fundamenta no conceito de APS já apontado, e tem como meta garantir um atendimento individual de boa qualidade, ao mesmo tempo em que procura dar respostas coletivas, nos casos necessários. Busca-se, assim, um distanciamento entre duas concepções assistenciais bastante influentes, que propõem uma assistência massificada e baseada em indicadores epidemiológicos, para a população pobre, e um atendimento restritamente individuali- zado e baseado em um raciocínio fisiopatológico, para as camadas de maior poder aquisitivo.

O posto oferece atendimento médico (que inclui a acupuntura e fitoterapia), odontológico, psicológico, fonoaudiológico e fisiátrico (antiginástica) e a clientela, embora tenha que chegar bastante cedo ao local para obter uma primeira consulta, é subseqüentemente agendada, com hora marcada. Os exames laboratoriais são colhidos na unidade e enviados diariamente ao Hospital da Lagoa (Ministério da Saúde), obtendo-se a maioria dos resultados em 24 horas. Existem diversos acordos com outros serviços da região para referência/contrareferência de pacientes, que funcionam de forma irregular. A maioria dos medicamentos prescritos é fornecida na unidade, a partir de um convênio com a Secretaria Municipal de Saúde - RJ, que também fornece material de consumo e al guns equipamentos. Além disso, o posto recebe diversas doações, tanto de moradores quanto de instituições filantrópicas e, em casos específicos, como pesquisas ou projetos especiais, é solicitado financiamento externo.

Por outro lado, a partir de questões surgidas nas consultas ou na comissão de saúde, são organizadas campanhas e programas epidemiológicos, dirigidos ao conjunto da comunidade. Cabe ressaltar que, em função do nível de participação existente, estas ações são realizadas com relativa facilidade e efetividade, a um custo bastante reduzido. Para dar alguns exemplos destas ações, podemos referir uma campanha para controle de um surto de escabiose, que resultou em dois mil tratamentos, uma vacinação de bloqueio de sarampo, e o Programa Comunitário de Controle da AIDS, que se desenvolve há cinco anos sem contar com nenhum recurso específico.

Em termos quantitativos, o posto realiza cerca de três mil atendimentos mensais. O índice médio de encaminhamentos é de 5,5\%, com $40 \%$ de contra-referências, e o índice de medicação, que se refere ao total de medicamentos industriais prescritos sobre o total de consultas, atinge a média mensal de $61 \%$. A solicitação de exames complementares (em relação ao número de consultas) apresenta a média de $34,8 \%$. Estes dados foram obtidos valendo-se de uma amostra aleatória de dez estatísticas mensais, entre as elaboradas a partir de 1988. Além destes indicadores, é levantado o perfil nosológico dos atendimentos, sendo que as três patologias mais prevalentes são, por ordem, as afecções respiratórias, a hipertensão arterial e as parasitoses. 
Da mesma forma que o trabal ho médico, os demais serviços buscam desenvolver um perfil específico de atendimento e, assim, são constantemente investigadas as peculiaridades da atenção à saúde mental nesta área, o mesmo ocorrendo em relação à odontologia e ao trabaIho de agentes de saúde. Não poderemos, aqui, aprofundar todos estes aspectos, mas vale a pena ressaltar que o próprio ambiente de autonomia e controle social sobre o serviço, é um fator de grande importância para a avaliação das metodologias propostas, e elaboração de novas formas de atuação. Queremos, com esta observação, apontar a existência de inter-relações entre o modelo organizativo na APS e o modelo assistencial, as quais emergem a partir do diálogo entre o conhecimento teórico-científico e o conhecimento, politicamente legitimado, das pessoas sobre suas condições de vida.

\section{Principais obstáculos encontrados no trabalho}

Em relação aos vários problemas enfrentados ao longo destes anos, destacamos dois, que consideramos mais importantes nesta discussão. O primeiro refere-se à questão do gerenciamento da unidade: durante vários anos a Associação dispôs de uma capacidade administrativa bastante reduzida, reflexo de sua própria fragilidade institucional, que provocava uma série de deficiências no serviço. Aos poucos, com o fortalecimento da entidade, em boa parte resultante do processo de crítica e suporte realizado pela Comissão de Saúde, foi sendo criada uma estrutura que tem sido suficiente para a manutenção da unidade, para a organização da documentação existente e da contabilidade. Um outro aspecto que teve bastante influência na melhoria da capacidade gerencial foi a possibilidade de remuneração indireta de alguns diretores da associação, que puderam, assim, ter mais disponibilidade para se dedicarem a este trabal ho. Uma outra al ternativa levantada durante as avaliações sobre o funcionamento da Associação, considerandose os constrangimentos estatutários da maioria destas entidades, que proíbem a remuneração de diretores, consistia na contratação de um secretário-geral, que teria a função administrativa cotidiana, prestando contas periodicamente à diretoria.

Um segundo problema, que tem tido bastante evidência atualmente, refere-se à relação das entidades comunitárias com o tráfico de drogas, cuja presença e influência nestes grupos populacionais é patente. No caso da AMABB, embora tenham ocorrido momentos de tensão, com algumas tentativas por parte do tráfico de interferir na Associação, a própria existência de um trabal ho de saúde respeitado na comunidade, bem como a sustentação política existente, a partir da Comissão de Saúde, foram suficientes para manter uma posição de independência na entidade. Aqui estamos utilizando o conceito de independência de uma forma restrita, no sentido de ligações diretas com o tráfico, já que existe um aspecto bem mais sutil e significativo desta questão, que refere-se ao próprio poder de normatização que o tráfico de drogas possui nas favelas, e que cria uma verdadeira cultura paralela, situando aquela instância enquanto a principal referência social dos moradores. Neste sentido, o processo que temos observado na Associação vem indicando o progressivo fortalecimento de uma alternativa ético-normativa baseada no recurso aos equipamentos de estado e na preocupação em incorporar as normas da sociedade mais geral, o que passa, por exemplo, pela regularização dos diversos aspectos legais da entidade. Este processo sugere que, de um modo mais geral, a questão do tráfico de drogas enquanto referência normativa se fortalece na exata medida da ausência de outras alternativas para o desenvolvimento pessoal e coletivo, e aqui estamos nos referindo não só aos aspectos materiais e econômicos, mas também, e principalmente, aos aspectos subjetivos relacionados à percepção de cidadania e ao modo de inserção e reconhecimento social dos moradores. Deste modo, acreditamos que, à proporção que as entidades comunitárias passem a ter uma responsabilidade mais formal e objetiva na implementação de políticas locais, elas encontrarão o incentivo suficiente para promoverem uma certa contracultura, em relação ao que tem sido chamado de "lei do morro" (Duarte et al., 1993).

Postos comunitários de APS: uma alternativa para a organização do sistema de saúde?

A partir desta breve apresentação, cabe agora avaliar os seus aspectos generalizáveis, que possam fundamentar a proposta de difusão desta alternativa de organização da Atenção Primária à Saúde. Um primeiro ponto, bastante óbvio, é que, para o usuário, é certamente mais confortável física e emocionalmente obter seu atendimento em um lugar próximo de sua casa, com profissionais que já conhece e pelos quais é conhecido. De fato, esta situação, por si só, já 
tem um conteúdo terapêutico. Também para os profissionais, a atuação dentro da comunidade permite uma qualidade diferenciada de visualização dos agravos à saúde, em relação a outras áreas de atuação, possibilitando um atendimento rico, do ponto de vista técnico, e uma maior possibilidade de retorno e avaliação de seus procedimentos. Ainda no aspecto técnico, a possibilidade de uma maior integração entre as ações "preventivas" e "curativas", contextualizadas em um local definido e sustentadas pela participação dos moradores, cria um maior potencial de controle sobre as enfermidades, atingindo níveis mais altos de eficiência e efetividade, quando comparadas às ações seletivas desenvolvidas por estímulos externos.

Por outro lado, unidades como a que descrevemos podem ser estruturadas com base no próprio interesse e disposição dos moradorese de suas entidades, sem a necessidade de um planejamento centralizado. Aqui, cabe assinalar que dezenas de comunidades já possuem instalações desativadas, ou que podem ser facilmente adaptadas para a assistência à saúde. Assim, trata-se apenas de estimular esta alternativa, que, além de atender às demandas sanitárias locais, possibilita o fortalecimento da autonomia e o desenvolvimento comunitário. Além disso, tendo em vista que estas entidades não têm fins lucrativos, pode-se esperar uma maior inversão dos recursos obtidos em meIhorias do serviço ou da própria comunidade. Esta última afirmação tem como pressuposto a possibilidade de um maior controle social sobre o trabalho, decorrente de suas próprias características locais, e, particularmente, na medida em que as entidades responsáveis possuam um caráter eletivo.

Uma outra questão refere-se à situação de violência vivida atualmente no interior das comunidades, o que poderia representar um fator limitador ao desenvolvimento da proposta. De fato, esta é uma situação objetiva, e existem alguns exemplos de trabalhos que foram inviabilizados por este motivo. Para abordar este problema, é necessário, em primeiro lugar, reconhecer a necessidade de avaliação prévia da localização das unidades, por parte das entidades responsáveis, evitando-se a utilização de espaços situados em áreas violentas. Em segundo, é preciso ter claro que esta situação não é uniforme, e existem diversas comunidades na verdade, a maioria delas - que apenas raramente convivem com momentos de maior tensão, o que, al iás, é atual mente uma característica urbana geral. Por último, cabe reafirmar nossa opinião de que é exatamente a possibilidade de alcançar uma posição social de maior progresso, reconhecimento e cidadania, um dos fatores cruciais para uma redução sustentada do perfil de violência ora observado.

Algumas propostas específicas para uma melhor estruturação dos postos de APS

Apresentamos, agora, algumas propostas de caráter prático, que poderão facilitar significativamente a estruturação de postos comunitários, sob a perspectiva de convênio com o SUS, evitando-se, com isto, uma boa parte dos problemas que foram, ou ainda são, enfrentados no Posto da AMABB. Uma primeira questão refere-se à importância do apoio à informatização destas unidades, que facilitará enormemente tanto a avaliação técnica, quanto a elaboração de faturas e administração contábil do serviço. Seria conveniente, neste sentido, o suporte para a aquisição de equipamentos, bem como para o desenvolvimento de programas (softwares) específicos, o que poderia ser conseguido através da iniciativa privada, ou do próprio governo.

Do ponto de vista do financiamento, as dificuldades encontradas para a sustentação do trabalho são as mesmas que, atualmente, toda a rede conveniada ao SUS vivencia, isto é, a defasagem na remuneração dos procedimentos. Para minorar os efeitos desta situação, e considerando os aspectos sociais e assistenciais envolvidos na proposta, sugerimos as seguintes modificações na remuneração dos serviços:

- Inclusão dos códigos da tabela SIA/SUS do grupo AVEIANM, atualmente restritos ao serviço público.

- Extensão dos códigos 045-0 (consulta médica diferenciada) e 027-2 (programa de agentes comunitários do Ministério da Saúde) aos postos de APS.

O primeiro item refere-se a todo um conjunto de procedimentos ligado às práticas preventivas e de educação em saúde, que atualmente encontram-se vinculados exclusivamente a instituições governamentais. O segundo abrange critérios específicos de remuneração de serviços médicos executados em regiões de pouca concentração destes profissionais, como pequenas cidades e áreas rurais, e as ações realizadas dentro de um programa de extensão de cobertura assistencial baseado na atuação de agentes de saúde, patrocinado pelo Ministério da Saúde.

Em relação aos mecanismos de el aboração de convênios, propomos que sejam regulamentados convênios diretos com associações de 
moradores, à semel hança do que já ocorre em relação a sindicatos, cooperativas, clínicas privadas, prefeituras, universidades, entidades filantrópicas etc. Esta medida, que nos parece bastante simples do ponto de vista técnico-jurídico, evitará uma série de inconvenientes oriundos da intermediação dos convênios por entidades filantrópicas, como o pagamento de taxas de administração e a falta de autonomia eventualmente gerada pela dependência formal das associações de moradores em relação àquelas entidades. Esta medida significará, também, o reconhecimento, por parte do Estado, da legitimidade e importância social das entidades representativas da comunidade, e de seu lugar na construção e democratização da cidadania.

\section{Conclusão}

A alternativa que propusemos neste texto concilia uma série de fatores que fazem parte do atual debate sobre políticas públicas, bem como das aspirações de amplos setores da população: melhor assistência à saúde, reconhecimento da cidadania (particularmente do direito a idéias e iniciativas), desenvolvimento so- cial, participação política. Talvez, mais do que apresentar uma proposta, busquemos dar visibilidade a uma tendência que, acreditamos, irá se fortalecer, à medida que as entidades comunitárias tomem conhecimento desta possibilidade, e também devido ao fato de que esta não necessita, a priori, de nenhuma estratégia especial que envolva recursos ou apoio político específicos. Certamente, a assinatura de convênios terá que contar com a sensibilidade dos Secretários Municipais de Saúde, mas acreditamos que a pressão das comunidades, ou, por outro lado, a atraente possibilidade de apoio político futuro, serão fatores suficientes para obter esta colaboração.

Entretanto, uma série de medidas pode ser tomada para incentivar esta tendência, como expusemos ao longo deste trabalho. Caberá ao Ministério da Saúde avaliar as condições para facilitar a elaboração e financiamento destes convênios; caberá às universi dades a formulação de modelos formativos adaptados a estes serviços. Finalmente, será competência nossa, profissionais de saúde, reconhecer que precisamos das iniciativas e da capacidade criativa da população para solucionarmos os crônicos problemas de todos nós.

\section{Referências}

ALMEIDA, L. L. \& CAMPOS, C. L., 1988. E a participação popular? In:. SaúdePara Todos. Desafio ao Município (D. Capistrano Filho \&A. L. Pimenta, orgs.), pp. 202-207, São Paulo: Hucitec.

DUARTE, L. F. D.; BARSTED, L. L.; TAULOIS, M. R. \& GARCIA, M. H., 1993. Vicissitudes e limites da conversão à cidadania nas classes populares brasileiras. Revista Brasileira de Sociologia, 22:5-19.

FERNANDES, J. C. L., 1996. Atenção Primária à Saúde: Uma Especialidade Médica? Dissertação de Mestrado, Rio de Janeiro: Instituto de Medicina Social, Universidade do Estado do Rio de Janeiro.

FREIRE, P., 1975. Pedagogia do Oprimido. Rio de Janeiro: Paz e Terra.

FOU CAULT, M., 1987. O Nascimento da Clínica. Rio de Janeiro: Editora Forense Universitária.

IMS-UERJ (Instituto de Medicina Social da Universidade do Estado do Rio de Janeiro). 1993. Avaliação das Condi ções para a Implantação de Distritos Sanitários em Áreas Rurais. Relatório Final. Rio de Janeiro: UERJ.
LACOMBE, R. \& POIRIER, L., 1992. The Québec network of "Villes et Villages en Santé". Encontro Anual de Coordenadores das Redes Nacionais de Cidades Saudáveis. Eindhoven. (mimeo.)

NOVAES, H. M., 1990. Ações Integradas nos Sistemas Locais de Saúde- SILOS. São Paulo: Livraria Pioneira e Editora.

OPS (ORGANIZACION PANAMERICANA DE LA SALUD), 1987. Esquema Tentativo para el Análisis de las Implicaciones de APSY SPT/2000. Washington: OMS. (mimeo.)

PS.AM ABB (Posto de Saúde da Associação de Moradores e Amigos do Bairro Barcelos), 1986. Perfil da Clientela. Rio de Janeiro: PS.AMABB.

RIFKIN, S. B. \& WALT, G., 1986. Why health improves: defining the issues concerning comprehensive primary health care' and 'selective primary health care'. Social Scienceand Medicine, 23:559-566.

ROSANVALLON, P., 1985. La Crise del'État-Providence. Paris: Éditions du Seuil. 